\title{
Conservative management of postoperative bronchopleural fistulas
}

\author{
Mohamed Sadok Boudaya, MD, ${ }^{\mathrm{a}}$ Hanène Smadhi, MD, ${ }^{\mathrm{a}}$ Hazem Zribi, MD, ${ }^{\mathrm{a}}$ Jalel Mohamed, MD, \\ Jamel Ammar, MD, ${ }^{\mathrm{b}}$ Taher Mestiri, MD, ${ }^{\mathrm{a}}$ and Tarek Kilani, MD ${ }^{\mathrm{a}}$
}

\begin{abstract}
Objective: A bronchopleural fistula (BPF) is a serious complication after pulmonary resection and carries a high mortality rate. It remains a therapeutic challenge. The lack of a consensus suggests that no optimal therapy is available; however, endoscopic closure of a fistula may avoid extensive and potentially risky surgery.
\end{abstract}

\begin{abstract}
Methods: Seventeen patients ( 15 men and 2 women) with a BPF after a pneumonectomy $(n=2)$ or a lobectomy $(n=15)$, seen between 1995 and 2010, were reviewed. Their median age was 50 years (range, 14-75 years). Underlying diseases were malignant $(n=4)$ and nonmalignant $(n=13)$.
Results: The mean interval between surgery and fistula development was 20 days (range, 5-270 days). Clinical symptoms leading to a diagnosis of BPF were a persistent air leak $(\mathrm{n}=2)$, a persistent air leak associated with pleural empyema $(\mathrm{n}=3)$, pleural empyema alone $(\mathrm{n}=11)$, and dyspnea $(\mathrm{n}=1)$. Mean fistula size was $3.3 \mathrm{~mm}$ (range, 2-9 mm). Treatment consisted of oriented pleural drainage, adequate antibiotic therapy, and endoscopic closure of the fistula with local application of silver nitrate through a flexible bronchoscope (3-15 sessions, 3 times per week). Fistula closure was successful in 16 patients, but failed in 1 patient, who died from acute respiratory distress.
\end{abstract}

Conclusions: BPF is a severe complication in thoracic surgery. The combination of pleural drainage, adequate antibiotic treatment, and mucosal application of silver nitrate, through a flexible bronchoscope, is an efficient alternative and avoids extensive surgical intervention. (J Thorac Cardiovasc Surg 2013;146:575-9)

A bronchopleural fistula (BPF) is a cavity that develops between the bronchial tree and the pleural space. It is a severe complication after pulmonary resection and carries a high mortality rate, ranging from $25 \%$ to $67 \%{ }^{1,2}$ The management of this serious postoperative complication remains a challenge. Therapeutic options range from extensive surgical procedures, including trans-sternal mediastinal closure of the BPF, a repeat thoracotomy, thoracoplasty, or chest-wall fenestration, followed by filling the cavity, to several other conservative bronchoscopic techniques. $^{3}$

Closure of a fistula using endoscopy constitutes a therapeutic alternative, and can avoid major surgery. Thus, although a wide variety of bronchoscopic procedures have been developed recently, no gold standard has yet been established regarding the treatment of choice. Therefore, we aimed, in this retrospective study, to evaluate the effectiveness and safety of applying silver nitrate onto the bronchial mucosa using a flexible bronchoscope.

\footnotetext{
From the Thoracic and Cardiovascular Surgery Department ${ }^{\mathrm{a}}$ and the Pulmonary Disease Service B, ${ }^{\mathrm{b}}$ University Hospital Abderrahmen Mami, Faculty of Medicine of Tunis, University of Tunis El Manar, Ariana, Tunisia.

Disclosures: Authors have nothing to disclose with regard to commercial support. Received for publication March 27, 2012; revisions received March 28, 2013; accepted for publication April 14, 2013; available ahead of print July 1, 2013.

Address for reprints: Hanène Smadhi, MD, Thoracic and Cardiovascular Surgery

Department, University Hospital Abderrahmen Mami, Ariana 1080, Tunisia

(E-mail: smadhi_hanen@yahoo.fr).

$0022-5223 / \$ 36.00$

Copyright (c) 2013 by The American Association for Thoracic Surgery

http://dx.doi.org/10.1016/j.jtcvs.2013.04.023
}

\section{METHODS}

We reviewed the records of all patients who had been treated for BPF in our thoracic surgery department between 1995 and 2010. During that period, we performed 1808 lobectomies (178 bilobectomies) and 427 pneumonectomies. We diagnosed 22 patients with BPF after a pneumonectomy (4 patients, $0.93 \%$ ) or a lobectomy ( 18 patients, $0.99 \%$ ). Five of these patients were excluded because they had not undergone bronchoscopy.

We included the data from 17 patients ( 15 men and 2 women) who had a postoperative bronchopleural fistula and had been treated with endoscopic injections of silver nitrate. Their median age was 50 years (range, 14-75 years). Resection had been conducted using the classic technique (ie, dissection of the different vascular elements bound by nonabsorbable thread, and these were then divided into sections). The bronchus of the area concerned was dissected, and then cut with a blade and sutured with Vicryl (Ethicon, Somerville, NJ) by applying cartilage onto cartilage or, less frequently, cartilage onto mucosa. The bronchial stumps were covered systematically by a pleural flap when the resection was on the right side.

Data were taken from hospital medical records and included age, underlying disease, side of the fistula, fistula size ( $\mathrm{mm})$ at initial bronchoscopy, interval (days) between surgery and fistula discovery, and mode and number of endoscopic interventions.

A diagnosis of a BPF was suspected if there were clinical signs of a persistent air leak, pleural empyema, dyspnea, or abundant sputum; radiological signs included a hydropneumothorax, empyema, atelectasis, or persistent pleural detachment. A diagnosis of a BPF was confirmed only if discontinuity of the stump was visualized by bronchoscopy. Endoscopic confirmation allowed us to avoid false positives.

The BPFs were divided according to the modified classification of Le Brigand into "early fistula" if it occurred 1 to 7 days after surgery, "intermediate" if it occurred 8 to 30 days after surgery, and "late" if it occurred more than 30 days after surgery. ${ }^{4}$ We treated 1 early, 8 intermediate, and 8 late fistulas.

Fistula sizes and their localizations were evaluated by a pulmonologist using fiberoptic endoscopy at the patient's bedside. If a BPF was suspected, immediate pleural drainage was performed, and specimens were taken for bacterial analysis. In cases of pleural empyema, an all-day irrigation 


\section{Abbreviation and Acronym \\ $\mathrm{BPF}=$ bronchopleural fistula}

system (using $50 \mathrm{~mL}$ of povidone-iodine in $500 \mathrm{~mL}$ of saline, diluted to $0.9 \%$, given at 0.5 to $1.5 \mathrm{~L} / 24 \mathrm{~h}$ ) was used for drainage and to control local infection. Pleural drainage was performed until the empyema had resolved. The chest tube could be removed when the drainage volume was less than $100 \mathrm{~mL} / 24 \mathrm{~h}$ and there were no air leaks or signs of a persistent fistula, as assessed by a radiological scan for incomplete lung expansion. All patients received antibiotic therapy adjusted according to their antibiogram.

Endoscopic treatment consisted of one or more sessions of mucosal application of silver nitrate to the edges of the fistula. Patients underwent flexible bronchoscopy under local anesthesia of the laryngeal and tracheal airways using $1 \%$ lidocaine. The first bronchoscopy assessed the lesions: it gathered information on the bronchial stump and the number, location, and size of the fistula(s). Thus, the fistula was recognized either directly, within the bronchial orifice as it opened directly into the pleural cavity (a large fistula), or indirectly, by seeing bubbling at the bronchial stump during coughing or aspiration.

We used liquid $1 \%$ silver nitrate that had been prepared in an adequately aerated room to avoid inspiration of its harmful vapors. A catheter (Combicath 58223.19; Prodimed, Saint-Leu-La-Forêt, France) was often used to apply the silver nitrate for protection during distal bacteriological sampling during resuscitation. A flexible bronchoscope was then positioned at 6 to 7 $\mathrm{mm}$ from the orifice of the fistula; the mucosal secretions were continuously aspirated. Under direct vision, the silver nitrate applicator was passed through the working channel of the bronchoscope, and $1 \mathrm{~mL}$ of the solution was administered around the fistula's mucosa. During this time, the patient did not cough and avoided inhalation. The applicator was then retracted. The procedure was repeated 3 times a week until closure of the BPF. The criteria for a good result were the appearance of inflammation around the edges of the fistula and a reduction in its size during the treatment period.

Before using this method, permission from our institution's ethics committee was obtained. Silver nitrate was used after its modality had been explained and after obtaining each patient's consent. The patients received regular checkups after discharge from the hospital. After 1 month, the patients' clinical data were monitored, and a chest radiograph and results from flexible fiberoptic endoscopy were assessed.

\section{RESULTS}

Seventeen patients (15 men and 2 women; mean age, 50 years; range, 14-75 years) with postoperative BPF were treated using a conservative nonsurgical method. Their underlying diseases were malignant (4 patients) and nonmalignant (13 patients: 4 with bronchiectasis, 2 with pulmonary hydatidosis, 2 with pseudotumoral tuberculosis, 3 with a chronic pulmonary abscess, 1 with aspergilloma, and 1 with infected bullous emphysema).

Fifteen patients had undergone a lobectomy (13 right lobectomies) and 2 had undergone a right pneumonectomy. The margins around the surgical incisions in patients who had a malignant disease were negative in frozen sections.

Clinical symptoms that led to a diagnosis of BPF were a persistent air leak $(\mathrm{n}=2)$, a persistent air leak associated with pleural empyema $(\mathrm{n}=3)$, pleural empyema alone ( $\mathrm{n}=11$, identified from drainage fluids), and dyspnea $(\mathrm{n}=1)$. Ten patients had abundant sputum. Chest $\mathrm{x}$-ray films showed hydropneumothorax $(\mathrm{n}=6)$, empyema $(\mathrm{n}=8)$, atelectasis $(\mathrm{n}=1)$, and persistent pleural detachment $(\mathrm{n}=2)$.

The mean interval between surgery and discovering the fistula was 20 days (range, 5-270 days). The median diameter of the BPF orifice was $3.3 \mathrm{~mm}$ (range, 2-9 mm). Fifteen patients had a fistula of $5 \mathrm{~mm}$ or smaller. In all patients, BPFs were localized on the bronchial stump, and 15 patients had a fistula on the right side.

For the 16 patients who survived, the mean duration of pleural drainage was 25 days (range, 4-70 days). Prophylactic antibiotherapy was given to all patients and was adjusted according to data from an antibiogram if one or more pathogens were isolated.

Fourteen patients had their chest tube removed during the hospital stay. For 2 patients, empyema was not adequately controlled by pleural drainage, despite complete fistula closure; thus, these patients were discharged with permanent drainage.

The endoscopic procedure required 3 to 15 sessions, at an average of 3 sessions per week. The median time until fistula closure was 14.5 days (range, 5-45 days). We did not observe any complications during treatment with endoscopy.

The fistula of 1 patient (patient 16, Table 1) was $9 \mathrm{~mm}$ in diameter. He was 55 years old, was obese, and had a medical history of diabetes mellitus and a cardiac pathology. He had undergone a right lower lobectomy for a chronic pulmonary abscess. At 10 days after surgery, he developed a right hydropneumothorax. Bronchoscopy showed inflammation of the middle bronchus and a large fistula in the right lower bronchus stump. Because of the patient's general status and, in particular, his medical history, we decided to treat him bronchoscopically with a local application of silver nitrate to avoid life-threatening surgery. He received 15 sessions, which resulted in successful complete closure of the fistula and no complications from the endoscopic treatment (Figure 1).

A BPF failed to close in a 75-year-old patient who had undergone surgery (a right lower lobectomy) for a tissular mass. The histological diagnosis was a metastatic pleomorphic carcinoma. He received 5 sessions of a silver nitrate application, but he died of acute respiratory distress syndrome related to aspiration pneumonia. Successful closure of the fistula occurred in all the patients who survived $(94.1 \%$ treatment success).

Patients were re-examined bronchoscopically at 1 and 6 months after bronchoscopy, and no relapses occurred. The overall average follow-up was 2 years, and patients were then transferred to a pulmonologist for continued management.

\section{DISCUSSION}

A BPF is the most serious postoperative complication after lung resection, and can depend on the surgeon's 
TABLE 1. Patient characteristics and outcomes classified chronologically

\begin{tabular}{|c|c|c|c|c|c|c|c|c|c|c|}
\hline $\begin{array}{l}\text { Patient } \\
\text { no. }\end{array}$ & Sex & $\begin{array}{c}\text { Age, } \\
\mathbf{y}\end{array}$ & Surgical treatment & $\begin{array}{c}\text { Size of } \\
\text { BPF, } \\
\text { mm }\end{array}$ & $\begin{array}{l}\text { Time from } \\
\text { surgery, } d\end{array}$ & $\begin{array}{c}\text { Complications, } \\
\text { symptoms }\end{array}$ & $\begin{array}{c}\text { No. of } \\
\text { bronchoscopy } \\
\text { sessions } \\
\end{array}$ & $\begin{array}{c}\text { Time of } \\
\text { closure, } \mathbf{d}\end{array}$ & $\begin{array}{c}\text { Outcome of } \\
\text { treatment }\end{array}$ & Follow-up \\
\hline 1 & M & 14 & Left lower lobectomy & 5 & 36 & Fever, pyopneumothorax & 6 & 20 & Definitive closure & No relapse \\
\hline 2 & M & 27 & Right lower lobectomy & 2 & 60 & $\begin{array}{l}\text { Fever, cough, pleural } \\
\text { empyema }\end{array}$ & 5 & 27 & Definitive closure & No relapse \\
\hline 3 & M & 19 & Right lower lobectomy & 2 & 5 & Fever, pyopneumothorax & 5 & 14 & Definitive closure & No relapse \\
\hline 4 & $\mathrm{~F}$ & 50 & Left lower lobectomy & 3 & 39 & $\begin{array}{l}\text { Chest pain, pleural } \\
\text { empyema }\end{array}$ & 6 & 17 & Definitive closure & No relapse \\
\hline 5 & M & 58 & Right lower lobectomy & 2 & 34 & $\begin{array}{l}\text { Fever, chest pain, pleural } \\
\text { empyema }\end{array}$ & 6 & 20 & Definitive closure & No relapse \\
\hline 6 & M & 65 & Bilobectomy & 5 & 15 & Fever, pleural empyema & 5 & 22 & Definitive closure & No relapse \\
\hline 7 & M & 50 & Right lower lobectomy & 5 & 13 & $\begin{array}{l}\text { Fever, persistent air leak, } \\
\text { pleural empyema }\end{array}$ & 5 & 19 & Definitive closure & No relapse \\
\hline 8 & $\mathrm{~F}$ & 31 & Bilobectomy & 1.5 & 30 & Chest pain, pyopneumothorax & 6 & 14 & Definitive closure & No relapse \\
\hline 9 & M & 62 & Right pneumonectomy & 1 & 15 & Fever, pyopneumothorax & 3 & 10 & Definitive closure & No relapse \\
\hline 10 & $\mathrm{M}$ & 46 & Right pneumonectomy & 1 & 270 & Pleural empyema & 5 & 13 & Definitive closure & No relapse \\
\hline 11 & M & 63 & Right upper lobectomy & 2 & 45 & Pleural empyema & 5 & 14 & Definitive closure & No relapse \\
\hline 12 & $\mathrm{M}$ & 49 & Right upper lobectomy & 2 & 30 & Persistent pleural detachment & 2 & 5 & Definitive closure & No relapse \\
\hline 13 & $\mathrm{M}$ & 47 & Right upper lobectomy & 3 & 20 & Persistent air leak & 9 & 25 & Definitive closure & No relapse \\
\hline 14 & M & 37 & Left lower lobectomy & 2 & 15 & $\begin{array}{l}\text { Fever, chest pain, pleural } \\
\text { empyema }\end{array}$ & 8 & 18 & Definitive closure & No relapse \\
\hline 15 & M & 48 & Right upper lobectomy & 2 & 13 & $\begin{array}{l}\text { Fever, chest pain, persistent } \\
\text { air leak }\end{array}$ & 4 & 8 & Definitive closure & No relapse \\
\hline 16 & $\mathrm{M}$ & 55 & Right lower lobectomy & 9 & 15 & Hydropneumothorax & 15 & 45 & Definitive closure & No relapse \\
\hline 17 & M & 75 & $\begin{array}{l}\text { Right lower lobectomy; } \\
\text { pleomorphic carcinoma }\end{array}$ & 6 & 9 & Empyema, fever, atelectasis & 5 & 22 & Failure? & ARDS/death \\
\hline
\end{tabular}

$B P F$, Bronchopleural fistula; $M$, male; $F$, female; $A R D S$, acute respiratory distress syndrome.

experience, the use of neoadjuvant chemoradiation therapy, a right-sided pneumonectomy, the length of the bronchial stump, the type of bronchial closure, the predicted postoperative pulmonary function, and prolonged mechanical ventilation. $^{5}$

BPFs have been reported to occur in $4.5 \%$ to $20 \%$ of cases after a pneumonectomy and in $0.5 \%$ of cases after a lobectomy. ${ }^{1}$ Historically, the management of this complication has been a major challenge. It still occurs in $2 \%$ to $5 \%$ of all pulmonary resections. ${ }^{6}$ In our series, we had an incidence of $0.93 \%$ after a pneumonectomy and $0.99 \%$ after a lobectomy. BPFs are associated with a serious mortality rate, ranging from $25 \%$ to $67 \% .^{7}$ The most common cause of death is aspiration pneumonia with subsequent acute respiratory distress syndrome, as occurred in the one patient who died in our study. The relationship between the increased incidence of BPFs and the use of staple sutures remains controversial.

The severity of the clinical features and the prognosis of $\mathrm{BPF}$ are related to the surgical procedure: BPF is more

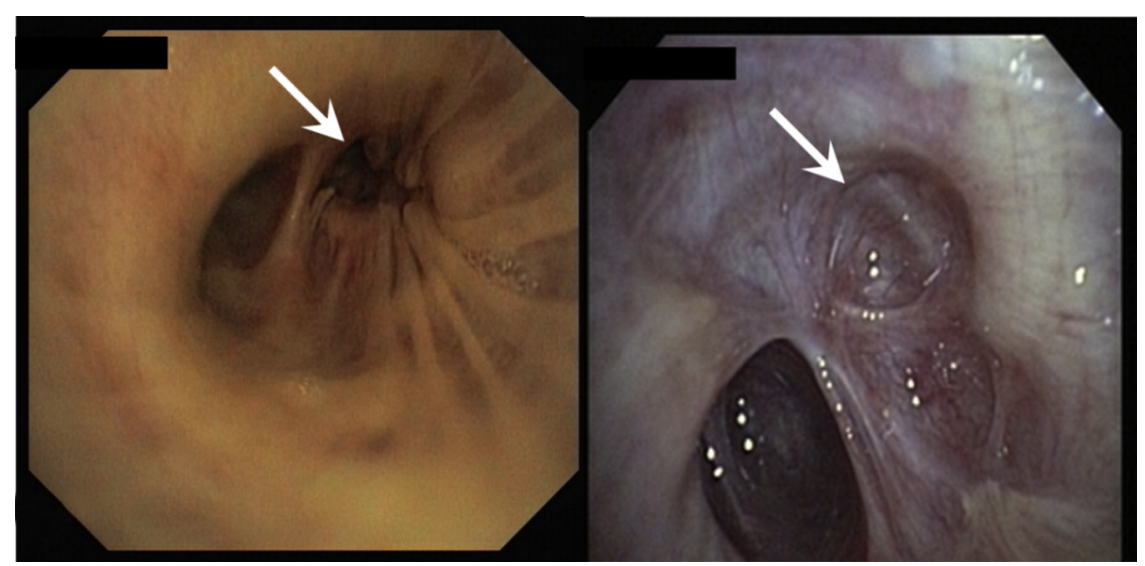

FIGURE 1. Patient 16. Left, Dehiscence of the right lower bronchus stump producing a large 9-mm bronchopleural fistula. Right, Successful bronchopleural fistula closure after 15 sessions of local application of silver nitrate. 
TABLE 2. Management of BPF with different materials

\begin{tabular}{|c|c|c|c|c|}
\hline Study & Year & Size & Material & Success rate, $\%$ \\
\hline$\overline{\text { Varoli }^{6}}$ & 1998 & 35 & Polidocanol & 65 \\
\hline Hollaus ${ }^{9}$ & 1998 & 29 & Fibrin glue & 35 \\
\hline Tsunezuka $^{10}$ & 1999 & 8 & Fibrin glue & 100 \\
\hline $\mathrm{Tao}^{11}$ & 2006 & 10 & Collagen screw plug & 90 \\
\hline $\operatorname{Singh}^{12}$ & 2005 & 1 & Stenting & 100 \\
\hline Hoier-Madson $^{13}$ & 1984 & 10 & $\begin{array}{l}\text { Silver nitrate (rigid } \\
\text { bronchoscope) }\end{array}$ & No details \\
\hline Stratakos ${ }^{7}$ & 2008 & 11 & $\begin{array}{l}\text { Silver nitrate (flexible } \\
\text { bronchoscope) }\end{array}$ & 81.8 \\
\hline Our study & 2010 & 17 & $\begin{array}{l}\text { Silver nitrate (flexible } \\
\text { bronchoscope) }\end{array}$ & 94.1 \\
\hline
\end{tabular}

frequent after a pneumonectomy. In fact, after a lobectomy, the expansion of the residual parenchyma can minimize the consequences of the fistula, whereas, after a pneumonectomy, bronchial leakage frequently happens and is associated with a high mortality rate, which can be up to $50 \%{ }^{6}$

The initial management of patients with BPF should include drainage of the infected pleural space, prophylactic antibiotics, and adequate clearance of bronchial secretions. The main challenge then remains to close the fistula. A variety of surgical and bronchoscopic strategies for treating BPFs have been described, ${ }^{5}$ although none of these approaches has been successful or suitable for all patients. ${ }^{8}$ The choice of treatment depends on the patient's functional status, how long until the BPF develops, and its size and clinical features.

Aggressive surgical options, such as open-window drainage, thoracoplasty, omentopexy, intrathoracic muscle transposition, and a trans-sternal mediastinal approach, can be problematic for an already compromised patient. ${ }^{7}$ Therefore, many physicians attribute great importance to more conservative treatments that involve drainage (and irrigation of the pleural empyema, if it is present) and endoscopic closure of the BPF.

We chose to not treat the fistula endoscopically when the stump was still open, because the edges of the fistula were still far apart: at that time point, the inflammation created by the silver nitrate was considered insufficient to close the orifice.

Several studies have been published on the application of different materials through a bronchoscope to close BPFs (Table 2). Varoli and colleagues ${ }^{6}$ investigated, in a series of 35 patients, the value of applying polidocanol through a flexible bronchoscope: this sclerotic agent is used frequently to treat esophageal varices. The authors reported that submucosal injections of polidocanol resulted in no serious technical difficulties and no complications and had a $65 \%$ success rate with permanent closure of fistulas measuring up to $10 \mathrm{~mm}$ in diameter. Hollaus and colleagues ${ }^{9}$ reported on 45 patients with a postoperative BPF, of whom 29 were treated endoscopically with fibrin glue or spongy calf bone. The authors reported a $35 \%$ success rate and concluded that the best results occurred in small, early fistulas. In addition, Tsunezuka and colleagues ${ }^{10}$ developed a tube system, made of 2-mm-diameter polypropylene, to endoscopically aerosolize fibrin glue (a biological adhesive) to treat BPFs of less than $2 \mathrm{~mm}$ in diameter: they achieved a $100 \%$ success rate.

Tao and colleagues ${ }^{11}$ designed an experimental animal (dog) model for BPF occlusion using a collagen screw plug. They hypothesized that the application of collagen, which promotes cellular proliferation and wound healing, would lead to a more favorable outcome: it successfully treated 9 of 10 dogs that had a BPF of less than $8 \mathrm{~mm}$ in diameter. Singh and colleagues ${ }^{12}$ reported successful closure of a large post-pneumonectomy BPF using a tracheobronchial stent procedure in a 75-year-old woman. The aim of stent placement was to curtail an air leak and allow effective lung ventilation.

In this study, we present evidence for the management of postoperative BPF using local application of silver nitrate through a flexible bronchoscope.

The first use of silver nitrate was by Hoier-Madson and colleagues ${ }^{13}$ in 1984 . They successfully treated 10 patients with BPF, after a pneumonectomy for non-small cell lung cancer, through a rigid bronchoscope. The application of silver nitrate caused tissue burns and local inflammation, followed by the normal healing process and scar formation, which achieved closure of the fistula. However, we have no details of the exact techniques used or of the clinical findings or follow-up data.

This technique was not repeated until 2008, when Stratakos and colleagues ${ }^{7}$ investigated the value of silver nitrate applied to a BPF through a flexible videobronchoscope. Eleven patients with 5-mm BPFs or smaller were enrolled in their study. All underwent flexible videobronchoscopy under conscious sedation. The authors used a standard bronchoscopic cytology brush to apply the silver nitrate. Drops of melted silver nitrate covered the entire surface of the cytology brush and solidified. The bronchoscope was positioned as close as possible to the orifice of the fistula, and the cytology brush was then passed through the working channel of the bronchoscope and rubbed against the mucosal borders of the fistula in a circumferential movement for 5-s sessions until blanching and edema of the mucosa appeared. The applicator was then retracted. This procedure was repeated up to 10 times at intervals of 5 to 7 days until the fistula had sealed effectively. The treatment procedure required a mean of 2.5 (range, 1-10) bronchoscopic sessions of silver nitrate application and resulted in complete closure of the BPF in 9 patients ( $81.8 \%$ treatment success), but closure failure in 2 patients (18.18\% treatment failure).

In our study, we enrolled 17 patients who had developed post-pneumonectomy or post-lobectomy BPF with a fistula size that ranged from 2 to $9 \mathrm{~mm}$. In contrast to previous 
reports, we did not exclude patients with a fistula size of 5 $\mathrm{mm}$ or greater. All patients were treated using a flexible videobronchoscope under local anesthesia. We used an intravenous catheter to apply the silver nitrate. The results from the local application of this caustic material were encouraging. Effective and uneventful closure of the fistula was accomplished in 16 patients ( $94.1 \%$ treatment success), plus clinical status was improved. There was only one failed BPF closure, and this was in an aged patient with a poor clinical status. Unlike the results of Stratakos and colleagues, we needed the application of silver nitrate associated with drainage and antibacterial therapy to obtain a good result.

Treatment of BPFs is not based solely on the management of the fistula but also involves drainage and irrigation of the pleura, and treating any infection with appropriate antibiotics. This 3-pronged approach allows a global treatment of the various components of this complication.

\section{CONCLUSIONS}

A BPF, although rare, is a therapeutic challenge and is associated with a high rate of morbidity and mortality. The management of this postoperative complication includes various surgical and medical procedures, including the recent interest in endoscopic methods. Most of these interventions have been described in series and case reports, but no overall consensus has been established. Treatment needs to be individualized. In high-risk surgical patients, endoscopic procedures may serve as a temporary alternative until the patient's clinical status has improved; however, in other patients, endoscopic treatment may be the only option.

In our experience, we found that the application of silver nitrate to mucosal tissue through a fiberoptic bronchoscope was easy, safe, nontraumatic, and effective: it allowed successful closure of postoperative BPFs, even large fistulas (up to $9 \mathrm{~mm}$ ), and avoided the need for major surgical intervention.

\section{References}

1. Cerfolio RJ. The incidence, etiology and prevention of postresectional bronchopleural fistula. Semin Thorac Cardiovasc Surg. 2001;13:3-7.

2. Sirbu H, Bush T, Alecsic I, Schreiner W, Oster O, Dalichau H. Bronchopleural fistula in the surgery of nonsmall cell lung cancer: incidence, risk factors and management. Ann Thorac Cardiovasc Surg. 2001;7:330-6.

3. Lois M, Noppen M. Bronchopleural fistulae: an overview of the problem with special focus on endoscopic management. Chest. 2005;128:3955-65.

4. Le Brigand H. Fistules bronchiques après pneumonectomies. In: Le Brigand H, ed. Appareil Respiratoire, Mediastin, Paroi Thoracique. Paris, France: Ed Masson; 1973;XXII:462-70.

5. Groth SS, D'Cunha J, Rueth NM, Andrade RS, Maddaus MA. Mediastinoscopyassisted minimally invasive closure of a bronchopleural fistula: a new technique to manage an old problem. J Thorac Cardiovasc Surg. 2010;140:244-5.

6. Varoli F, Roviaro G, Grignani F, Vergani C, Maciocco M, Rebuffat C. Endoscopic treatment of bronchopleural fistulas. Ann Thorac Surg. 1998;65:807-9.

7. Stratakos G, Zuccatosta L, Porfyridis I, Sediari M, Zisis C, Mariatou V, et al. Silver nitrate through flexible bronchoscope in the treatment of bronchopleural fistulae. J Thorac Cardiovasc Surg. 2009;138:603-7.

8. Scappaticci E, Ardissone F, Ruffini E, Baldi S, Mancuso M. Postoperative bronchopleural fistula: endoscopic closure in 12 patients. Ann Thorac Surg. 1994;57: 119-22.

9. Hollaus PH, Lax F, Janakiev D, Lucciarini P, Katz E, Kreuzer A, Pridun NS. Endoscopic treatment of postoperative bronchopleural fistula: experience with 45 cases. Ann Thorac Surg. 1998;66:923-7.

10. Tsunezuka Y, Sato H, Tsukioka T, Hiranuma C. A new instrument for en doscopic gluing for bronchopleural fistulae. Ann Thorac Surg. 1999;68: 1088-9.

11. Tao H, Araki M, Sato T, Morino S, Kawanami R, Yoshitani M, Nakamura T, Bronchoscopic treatment of postpneumonectomy bronchopleural fistula with a collagen screw plug. J Thorac Cardiovasc Surg. 2006;132:99-104.

12. Singh SS, Pyragius MD, Shah PJ, Stubberfield J, Jurisevic CA, Chaloob S. Management of a large bronchopleural fistula using a tracheobronchial stent. Heart Lung Circ. 2007;16:57-9.

13. Ginsberg RJ, Pearson FG, Cooper JD, Spratt E, Deslauriers J, Goldberg M, et al. Closure of chronic postpneumonectomy bronchopleural fistula using the transsternal transpericardial approach. Ann Thorac Surg. 1989;47:231-5. 